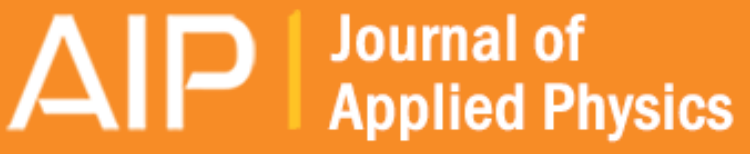

\section{Damp and dry heat degradation of thermal oxide passivation of $p+$ silicon}

Andrew Thomson, Matthew Gardner, Keith Mclntosh, Avi Shalav, and James Bullock

Citation: Journal of Applied Physics 115, 114505 (2014); doi: 10.1063/1.4869057

View online: http://dx.doi.org/10.1063/1.4869057

View Table of Contents: http://scitation.aip.org/content/aip/journal/jap/115/11?ver=pdfcov

Published by the AIP Publishing

\section{Articles you may be interested in}

Surface passivation of $\mathrm{n}$-type c-Si wafers by a-Si/SiO2/SiNx stack with

Appl. Phys. Lett. 103, 183903 (2013); 10.1063/1.4827821

High-quality surface passivation of silicon using native oxide and silicon nitride layers

Appl. Phys. Lett. 101, 021601 (2012); 10.1063/1.4733336

Modulation of atomic-layer-deposited Al2O3 film passivation of silicon surface by rapid thermal processing Appl. Phys. Lett. 99, 052103 (2011); 10.1063/1.3616145

Defect passivation in multicrystalline silicon for solar cells

Appl. Phys. Lett. 85, 4346 (2004); 10.1063/1.1815380

Field-effect passivation of the $\mathrm{SiO} 2 \mathrm{Si}$ interface

J. Appl. Phys. 86, 683 (1999); 10.1063/1.370784

\section{A|P $\left.\right|_{\text {Applied Physics }} ^{\text {Journal of }}$}

Journal of Applied Physics is pleased to announce André Anders as its new Editor-in-Chief 


\title{
Damp and dry heat degradation of thermal oxide passivation of $\boldsymbol{p}^{+}$silicon
}

\author{
Andrew Thomson, ${ }^{1}$ Matthew Gardner, ${ }^{1}$ Keith McIntosh, ${ }^{2}$ Avi Shalav, ${ }^{3}$ and James Bullock ${ }^{1}$ \\ ${ }^{1}$ Research School of Engineering, Australian National University (ANU), Canberra 0200, Australia \\ ${ }^{2}$ PV lighthouse, Coledale NSW 2515, Australia \\ ${ }^{3}$ Department of Electronic Materials Engineering, Australian National University (ANU), Canberra 0200, \\ Australia
}

(Received 29 January 2014; accepted 7 March 2014; published online 19 March 2014)

\begin{abstract}
Thermal $\mathrm{SiO}_{2}$ passivates both moderately and heavily doped silicon surfaces irrespective of the dopant type, which is advantageous in high-efficiency solar cell designs. Commercial photovoltaic cells are submitted to accelerated ageing tests, such as damp-heat exposure, to ensure they maintain their performance for at least $20 \mathrm{yr}$. We find damp-heat exposure causes a severe and rapid degradation of thermal $\mathrm{SiO}_{2}$ passivation on $\mathrm{p}^{+}$silicon surfaces. The reaction is so severe that the diffused-region recombination in the degraded state is limited by the diffusion of minority carriers to the $\mathrm{Si}-\mathrm{SiO}_{2}$ interface not the density of interface defects $\mathrm{D}_{i t}$. Certainly, this effect renders the thermal-oxide passivation useless if employed on a solar cell. To study the cause of the degradation, we also test the effects of storage in dry heat and room ambient conditions. Examination of the rate of degradation in the tested storage conditions in comparison with modelled diffusion of moisture in $\mathrm{SiO}_{2}$, we find a significant correlation between the time dependent $\mathrm{J}_{0 \mathrm{e}}$ and moisture supplied to the interface, leading us to the conclusion that moisture ingression and subsequent reaction at the $\mathrm{SiO}_{2}-\mathrm{Si}$ interface are the cause of both damp-heat and room- ambient degradation. (C) 2014 AIP Publishing LLC. [http://dx.doi.org/10.1063/1.4869057]
\end{abstract}

\section{INTRODUCTION}

Thermally grown $\mathrm{SiO}_{2}$ passivates crystalline-silicon surfaces by chemically deactivating recombination centers, thereby reducing the density of interface defects $D_{\mathrm{it}} \cdot{ }^{1}$ Unlike aluminum oxide and silicon nitride, the contribution of field-effect passivation for thermally oxidized surfaces is small owing to its low-insulator charge $Q_{\mathrm{f}}{ }^{2}$ The combination of low $D_{\text {it }}$ and $Q_{\mathrm{f}}$ enables $\mathrm{SiO}_{2}$ to effectively passivate both moderately and heavily doped surfaces irrespective of the dopant type. Hence, $\mathrm{SiO}_{2}$ is suitable for passivating interdigitated-back-contact (IBC) and high-efficiency front-junction solar cells, which require simultaneous passivation of $n^{+}$and $p^{+}$regions. $^{3,4}$

Commercial photovoltaic modules are routinely submitted to accelerated testing, including to damp-heat exposure at $85{ }^{\circ} \mathrm{C}$ and $85 \%$ relative humidity $(\mathrm{RH})$ for $1000 \mathrm{~h} .{ }^{5}$ To pass accelerated testing, the modules must preserve at least $95 \%$ of their rated output power. As standard encapsulation technology for crystalline-silicon cells does not prevent the ingression of moisture, ${ }^{6}$ it is important that the cell passivation schemes are stable under damp-heat exposure.

The stability of the $\mathrm{SiO}_{2}-\mathrm{Si}$ interface passivation has been studied in-depth for microelectronic applications. Stimuli such as moisture, ${ }^{7}$ radiation, ${ }^{1,8}$ film stress, ${ }^{9}$ thermal annealing, ${ }^{10}$ and combined electric-field stress and thermal annealing - negative bias temperature instability ${ }^{11}$ - degrade the $\mathrm{SiO}_{2}-\mathrm{Si}$ interface. $\mathrm{SiO}_{2}-\mathrm{Si}$ interface degradation reactions resulting from the aforementioned stimuli are caused by the reactions of hydrogenous species at or near the $\mathrm{SiO}_{2}-\mathrm{Si}$ interface. ${ }^{12}$ Photovoltaic related studies have found damp-heat exposure degrades $\mathrm{SiO}_{2}$ passivation. For both $n^{+}$ diffused and moderately doped $n$ - and $p$-type surfaces, a 3-5 fold increases in recombination has been observed, where the degradation reaction saturates in 7 days. ${ }^{13,14}$

In this work, we study thermal $\mathrm{SiO}_{2}$ passivated $p^{+}$surfaces exposed to the following storage conditions: damp heat at $85^{\circ} \mathrm{C}$ and $85 \% \mathrm{RH}$; dry heat at $85^{\circ} \mathrm{C}$ and $<5 \% \mathrm{RH}$; and at room temperature and $<15 \% \mathrm{RH}$ as summarized in Table I. We observe a more severe degradation of $p^{+}$surfaces exposed to damp heat than has been observed for $n^{+}$surfaces, whereby the emitter-saturation current density $J_{0 \mathrm{e}}$ increases from 40 to $2200 \mathrm{fA} / \mathrm{cm}^{2}$, saturating in four days. We find that dry-heat exposure exhibits a slower reaction where $J_{0 \mathrm{e}}$ increases from 40 to $330 \mathrm{fA} / \mathrm{cm}^{2}$ over the course of 160 days, whereupon the degradation reaction has not saturated. Samples exposed to room-temperature and low humidity also degrade but the reaction is slow and only observable after 40 days, where the $J_{0 \mathrm{e}}$ increases from 40 to $300 \mathrm{fA} / \mathrm{cm}^{2}$. Previous measurements of dry-heat and room-ambient exposure have been observed where similar but faster reactions were observed. ${ }^{15}$ (We note that in a preliminary study on damp-heat exposure of $\mathrm{SiO}_{2}$ passivated $p^{+}$ silicon, the experiment was likely compromised by the initial measurements commencing long after the samples had degraded in the room ambient. ${ }^{16}$ )

Significantly, this work directly investigates the different time scales and magnitudes of the degradation reactions by modeling the diffusion of water through $\mathrm{SiO}_{2}$ for the different storage conditions, similar to the theory discussed by Klampaftis et al. ${ }^{14}$ This paper demonstrates that damp-heat degradation is more severe for $p^{+}$surface as compared to published results on $n^{+}$surfaces. ${ }^{17}$ Indeed, a capping layer of silicon nitride may prevent the effects of damp-heat and room-ambient exposure, ${ }^{17,18}$ an important design consideration when attempting to fabricate stable solar cells with a $p^{+}$ 
TABLE I. Storage conditions used in this work. The samples were stored at room temperature, in a dry heat, or damp heat for $3820 \mathrm{~h}$. A fourth set of samples were initially stored in damp heat for $64 \mathrm{~h}$ then transferred to dry heat for remainder of the experiment.

\begin{tabular}{lcc}
\hline \hline Storage description & $\begin{array}{c}\text { Condition } 1 \\
\text { (Temp./RH) }\end{array}$ & $\begin{array}{c}\text { Condition 2 } \\
\text { (Temp./RH) }\end{array}$ \\
\hline Damp heat & $85^{\circ} \mathrm{C} / 85 \%$ & $\ldots$ \\
Room ambient & $25^{\circ} \mathrm{C} / \sim 15 \%$ & $\ldots$ \\
Dry heat & $85^{\circ} \mathrm{C} /<5 \%$ & $\ldots$ \\
Damp heat to dry heat & $85^{\circ} \mathrm{C} / 85 \%$ & $85^{\circ} \mathrm{C} /<5 \%$ \\
\hline \hline
\end{tabular}

surface. $^{3,19}$ This paper outlines our experimental procedure, then presents the degradation results, and finally results are discussed alongside calculations of moisture supplied to the $\mathrm{Si}-\mathrm{SiO}_{2}$ interface.

\section{EXPERIMENTAL}

We now summarize our experimental procedure, giving details on the sample fabrication, the measurement procedure, and the theory related to our modeling of moisture diffusion in thermal $\mathrm{SiO}_{2}$.

Photoconductance measurements were used to determine $J_{0 \mathrm{e}}$ of symmetrical boron-diffused test structures passivated by thermal $\mathrm{SiO}_{2}$. One day after fabrication, the wafers were exposed to the following atmospheric conditions (as outlined in Table I): (i) heated ambient at $85^{\circ} \mathrm{C}$ and $85 \%$ $\mathrm{RH}$-referred to as damp heat-where the samples were stored in a temperature and humidity controlled test chamber (Haida, HD-150 T), (ii) room temperature $\left(22-26^{\circ} \mathrm{C}\right.$ ) and dry air $(\sim 15 \% \mathrm{RH})$ - referred to as room ambient-where the samples were stored in an air-tight container with silica gel drying chips (Sigma Aldrich), and (iii) heated ambient at $85^{\circ} \mathrm{C}$ and $<5 \% \mathrm{RH}$-referred to as dry heat-where the samples were stored in an thermocouple-controlled atmospheric oven. The $J_{0 \mathrm{e}}$ was measured as a function of storage time for 3820 h (160 days). After 64 h, some samples stored in damp heat were removed from the test chamber and placed in storage under dry heat conditions to examine the reversibility of the degradation with and without a moisture source.

\section{A. Sample fabrication}

To fabricate test structures, $100 \mathrm{~mm}$ diameter float zone, (100) orientated, $1.16 \pm 0.04 \Omega \mathrm{cm}$, phosphorus-doped silicon wafers were acid-etched to remove saw damage and Radio Corporation America cleaned to remove organic and metallic impurities. All wafers received a symmetrical $p^{+}$ boron diffusion from a $\mathrm{BBr}_{3}$ source in a clean boron-diffusion quartz furnace (Tempress R\&D scale horizontal four-stack furnace). The borosilicate glass (BSG) was deposited at $900^{\circ} \mathrm{C}$ for $10 \mathrm{~min}$. The boron was subsequently driven in with an anneal in $\mathrm{N}_{2}$ for 10 min at $910{ }^{\circ} \mathrm{C}$ followed by an oxidation for $20 \mathrm{~min}$ at $920^{\circ} \mathrm{C}$. The BSG was removed in hydrofluoric acid to allow the growth of a high-quality $\mathrm{SiO}_{2}$ layer. A subsequent oxidation was performed in a clean oxidation quartz furnace (Tempress R\&D scale horizontal four-stack furnace). The oxidation was performed at $1000^{\circ} \mathrm{C}$ for 30 min followed by an in-situ anneal in $\mathrm{N}_{2}$ at $1050{ }^{\circ} \mathrm{C}$. Wafers were then subjected to a $400^{\circ} \mathrm{C}$ anneal in $\mathrm{Ar} / \mathrm{H}_{2}$ $95 \% / 5 \%$ forming gas for 30 min to hydrogenate the $\mathrm{Si}_{-} \mathrm{SiO}_{2}$ interface. The fabrication procedure described above led to 16 samples with a sheet resistance of $280 \pm 10 \Omega / \mathrm{sq}$, an $\mathrm{SiO}_{2}$ thickness of $25 \pm 10 \mathrm{~nm}$, and an initial effective lifetime of $510 \pm 100 \mu$ s at $1 \times 10^{15} \mathrm{~cm}^{-3}$, resulting from a bulk lifetime of $2.3 \pm 0.9 \mathrm{~ms}$ and a $J_{0 \mathrm{e}}$ of $47 \pm 9 \mathrm{fA} / \mathrm{cm}^{2}$.

The electrically active dopant profile, measured using WEP CVP21 electrochemical capacitance voltage (ECV) wafer profiler, of the $p^{+}$diffusion is plotted in Figure 1. We see that there is no significant surface depletion, owing to dopant redistribution during the high temperature anneal. The doping profiles measured by ECV were corrected in order to account for variability in the profiler's contact area. We followed a process outlined by Bock et al. ${ }^{20}$ which matches the sheet resistance predicted by the ECV profile to the four-point probe measured sheet resistance-using the mobility model in Ref. 21.

\section{B. Measurement of $\mathbf{J}_{0 e}$}

Photoconductance lifetime measurements were performed with a Sinton Instruments WCT-120. The measurements were taken under transient ${ }^{22}$ and quasi-steady state conditions with a generalized analysis, ${ }^{23}$ in accordance with the procedure detailed in Ref. 24.

Unlike the conventional approach of the Kane and Swanson method ${ }^{22,25}$ for $J_{0 \mathrm{e}}$ calculation, we do not make the assumption that the depthwise $\Delta n$ in the wafer is uniform. Instead, we find a more accurate $J_{0 \mathrm{e}}{ }^{25,26}$ by numerically solving the one-dimensional depthwise profile of $\Delta n$ considering the diffusion, recombination, and generation of carriers in the quasi-neutral bulk of a silicon sample such that the simulated $\Delta n$ averaged across the wafer $\Delta n_{\text {avg }}$ matches that of the measured $\Delta n_{\text {avg. }}$. Our measurement procedure necessitates the numerical solving of the partial differential equation given in Ref. 23 using the boundary conditions from Ref. 22. The error presented in the measurements of $J_{0 \mathrm{e}}$ (Figs. 3 and 4) represents the minimum and maximum sample-to-sample

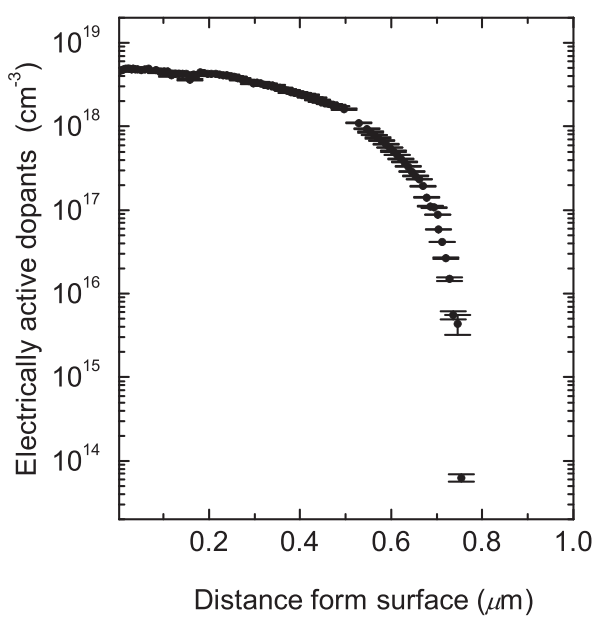

FIG. 1. ECV measured electrically active dopant profiles for the boron diffusion used to study the effect of moisture on $\mathrm{SiO}_{2}$ passivated $p^{+}$surfaces. 
variation, which is significantly greater than the uncertainty in the measurements. ${ }^{27}$

\section{Modeling of moisture diffusion}

To aid in the explanation of our measured $J_{0 \mathrm{e}}$ results, we have modelled the diffusion of moisture through $\mathrm{SiO}_{2}$ in order to determine the relative flux of water molecules supplied to the $\mathrm{SiO}_{2}-\mathrm{Si}$ interface for samples exposed to each of the three storage conditions. In this work Fickian diffusion is assumed, which in one dimension is represented by a generalized complementary error function of the form

$$
n_{T_{i}, R H_{\mathrm{j}}}(x, t)=n_{T_{i}, R H_{\mathrm{j}}}(0) \operatorname{erfc}\left(\frac{x}{2 \sqrt{D_{H 2 O}^{\left(T_{i}\right)} t}}\right),
$$

where $n_{T_{i}, R H_{\mathrm{j}}}(x, t)$ is the moisture concentration, $n_{T_{i}, R H_{\mathrm{j}}}(0)$ is a fixed concentration at the $\mathrm{SiO}_{2}$-air surface, and $D_{H 2 O}^{\left(T_{i}\right)}$ is the diffusion coefficient at temperature $T_{i}$. This model assumes an infinitely thick $\mathrm{SiO}_{2}$ layer. To account for a finite $\mathrm{SiO}_{2}$ thickness, we perform an integration to determine the total moisture supplied to the interface

$$
\mathrm{H}_{2} \mathrm{O}_{\text {int }}(t)=\int_{\infty}^{t_{\mathrm{ox}}} n(t)_{T_{i}, R H_{\mathrm{j}}} \cdot \mathrm{dx},
$$

where $t_{\mathrm{ox}}$ is the thermal oxide thickness and $n_{T_{i}, R H_{\mathrm{j}}}$ is calculated from Eq. (1). This calculation therefore makes the rough approximation that the interface absorbs $\mathrm{H}_{2} \mathrm{O}$ molecules at the same rate as they diffuse through silicon and that the interface is an infinite $\mathrm{H}_{2} \mathrm{O}$ sink. We view this metric as the time-dependent total supply of reactants available to cause degradation.

In order to calculate $\mathrm{H}_{2} \mathrm{O}_{\text {int }}(t)$, it is necessary to determine $n_{T_{i}, R H_{\mathrm{j}}}(0)$ and $D_{H 2 O}^{\left(T_{i}\right)}$ for the storage conditions listed in Table I. We determined $D_{H 2 O}^{(25)}$ and $D_{H 2 O}^{(85)}$ to be $(10 \pm 7)$ $\times 10^{-18}$ and $(6 \pm 5) \times 10^{-20} \mathrm{~cm}^{2} / \mathrm{s}$, respectively, by extrapolating the temperature dependent $D_{\mathrm{H} 2 \mathrm{O}}$ relationship of Moulson and Roberts. ${ }^{28}$ We are satisfied that the extrapolation is reasonable despite Moulson and Roberts' experimental data being taken at temperatures $600-1200^{\circ} \mathrm{C}$ because we independently determined $D_{H 2 O}^{(85)}$ by analyzing previously published secondary-ion-mass spectrometry (SIMS) measurements of hydrogen in $\mathrm{SiO}_{2}{ }^{17}$ The SIMS measurements were performed on $180 \mathrm{~nm}$ thermal $\mathrm{SiO}_{2}$ layers exposed to $85^{\circ} \mathrm{C}$ and $85 \% \mathrm{RH}$ damp heat for 0,1000 , and $10000 \mathrm{~min}$ and show the hydrogen concentration as a function of depth increasing with exposure time. ${ }^{17}$ It is clear that the SIMS measured hydrogen originates from the ingression of moisture, hence, the diffusion coefficient can be extracted from this data by fitting Eq. (1) to the measured hydrogen profiles. The SIMS calculated $D_{H 2 O}^{(85)}$ is in good agreement with the Moulson and Roberts' extrapolation, as evidenced in Figure 2, which plots the Moulson and Roberts data, their fit including their parameterized uncertainty, and our calculated $D_{H 2 O}^{(85)}$. We note that the extrapolation is also in agreement

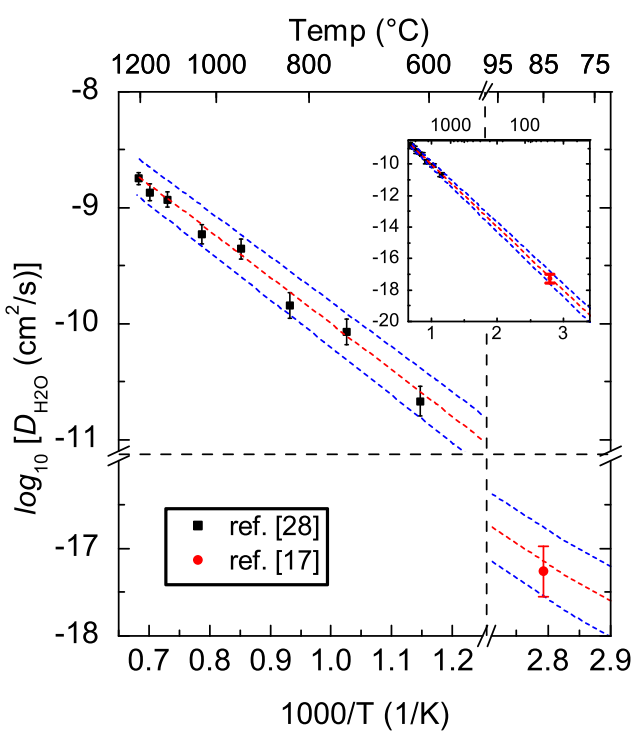

FIG. 2. Plot of temperature dependent diffusion coefficient for moisture in silica. High temperature data taken by Moulson and Roberts ${ }^{28}$ (black markers). The extrapolation of the Moulson and Roberts' diffusion relationship to low temperature is given by the dashed lines (red-the line of best fit, blue-the upper and lower confidence limits). Included in this plot is the $D_{\mathrm{H} 2 \mathrm{O}}$ calculated from the SIMS measurements presented by McIntosh and Dai. $^{17}$

with other low-temperature measurements of molecular $\mathrm{H}_{2} \mathrm{O}$ diffusion in $\mathrm{SiO}_{2}$, see Refs. 29 and 30.

In the modeling that follows below, $n_{85,85}(0)$ was set to be $1 \times 10^{20} \mathrm{~cm}^{-3}$, a value equivalent to the peak hydrogen concentrations in the SIMS measurements in Ref. 17. To determine $n_{25,15}(0)$, we consider the relative partial pressure of $\mathrm{H}_{2} \mathrm{O}$. From Henry's law, the partial pressure of $\mathrm{H}_{2} \mathrm{O}$ at $85^{\circ} \mathrm{C}$ and $85 \% \mathrm{RH}, P_{\mathrm{H} 2 \mathrm{O}}^{85,85}$, is proportional to the concentration of $\mathrm{H}_{2} \mathrm{O}$ at the $\mathrm{SiO}_{2}$ surface, that is $P_{H 2 O}^{85,85}=k_{\mathrm{H}}$ $\times n_{85,85}(0)$, where $k_{\mathrm{H}}$ is Henry's constant. Assuming $k_{\mathrm{H}}$ is not temperature dependent, which we suspect is reasonable over these small temperature ranges. The ratio of $k_{\mathrm{H}}$ under the different storage conditions is approximately equal to the ratio of the saturation partial pressures at the corresponding temperatures, implying that $n_{T_{i}, R H_{\mathrm{j}}}(0)$ is dependent mostly on humidity rather than temperature. Therefore, with knowledge of the partial pressures for each condition, we calculate $n_{25,15}(0) \approx\left(P_{H 2 O}^{25,15} / P_{H 2 O}^{85,85}\right)$ $\times n_{85,85}(0) \approx 0.18 \times n_{85,85}(0)$ and $n_{85,05}(0) \approx\left(P_{H 2 O}^{85,05} / P_{H 2 O}^{85,85}\right)$ $n_{85,85}(0) \approx 0.11 \times n_{85,85}(0)$.

\section{RESULTS}

Figure 3 plots $J_{0 \mathrm{e}}$ as a function of time for samples exposed to the storage conditions listed in Table I. We observe three characteristic degradation reactions: (i) damp-heat degradation where $J_{0 \mathrm{e}}$ increases from 40 to $2200 \mathrm{fA} / \mathrm{cm}^{2}$ saturating at around $100 \mathrm{~h}$ (Fig. 3(a)), (ii) dry-heat degradation where $J_{0 \mathrm{e}}$ increases from 40 to 330 $\mathrm{fA} / \mathrm{cm}^{2}$ without saturating over $3820 \mathrm{~h}$ (Fig. 3(b)), and (iii) room-ambient degradation where the increasing $J_{0 \mathrm{e}}$ becomes significant after $1000 \mathrm{~h}$ (Fig. 3(b)). In addition, we plot $J_{0 \mathrm{e}}$ for samples that were removed from damp heat 
(after partial degradation) to dry heat over the course of the experiment (Fig. 3(a)).

For reference, we have included previously published measurements of $J_{0 \mathrm{e}}$ for samples stored in similar conditions in Figure 3. In Fig. 3(a), we have included measurement of $J_{0 \mathrm{e}}$ for thermal oxide passivated $n^{+}$phosphorus-diffused surfaces as a function of time from McIntosh and Dai. ${ }^{17}$ These samples have a similar $\mathrm{SiO}_{2}$ thickness $(25 \pm 5 \mathrm{~nm})$ and were lightly diffused $(210 \pm 10 \Omega / \mathrm{sq})$. The degradation occurs over a similar time scale; however, the magnitude of the degradation is less severe. In Fig. 3(b), we also include previously published degradation data for thermal oxide passivated $p^{+}$diffusions. ${ }^{15}$ There are significant differences in the rate and magnitude of the degradation for the previously published results, especially when comparing the room ambient with the dry-ambient results.

(a) $\diamond$ Damp Heat $\left(85^{\circ} \mathrm{C}, 85 \%\right) \triangle$ Damp Heat to Dry Heat

* Damp Heat $\left(85^{\circ} \mathrm{C}, 85 \%\right)$ from ref. [17] on $n^{+}$

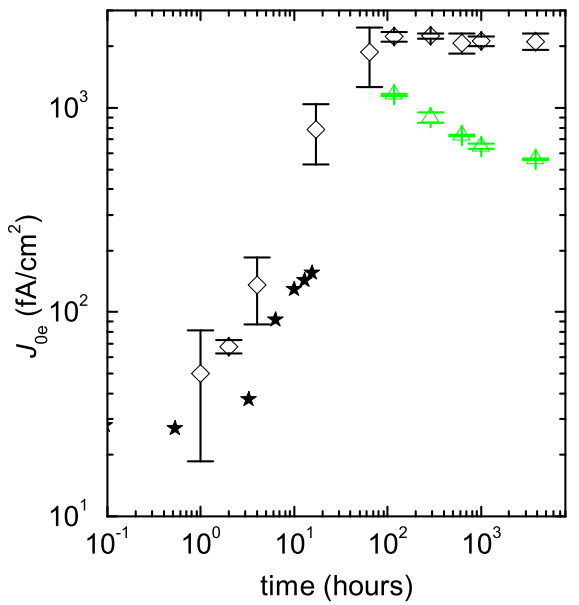

(b) Dry ambinet $\left(25^{\circ} \mathrm{C}, 15 \%\right)$ this work $\bigcirc$ Dry heat $\left(85^{\circ} \mathrm{C},<5 \%\right)$ this work II Room ambient $\left(25^{\circ} \mathrm{C}, \sim 30 \%\right)$, ref $[15]$. Dry heat $\left(75^{\circ} \mathrm{C},<5 \%\right)$, ref. $[15]$

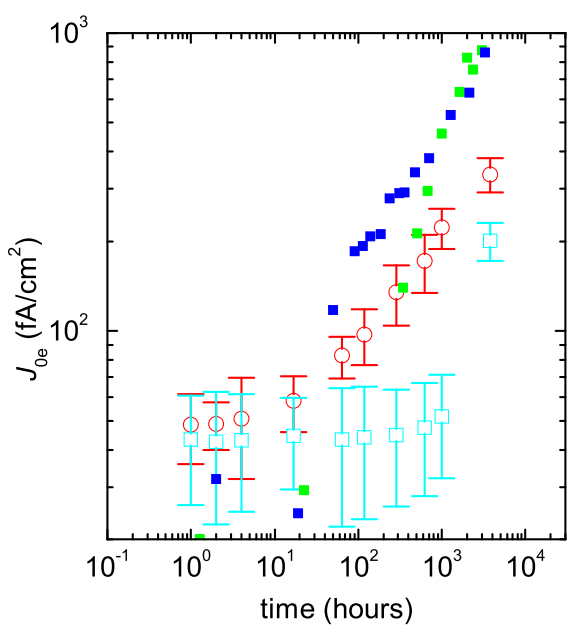

FIG. 3. Graph (a) plots $J_{0 \mathrm{e}}$ as a function of time for samples exposed to damp heat (black diamonds), and samples removed from damp heat to dry heat (green triangles). For comparison, we have plotted the $J_{0 \mathrm{e}}$ as a function of time measured by McIntosh and Dai ${ }^{17}$ (black stars), where in this case the surfaces were $n^{+}$phosphorus diffused not $p^{+}$boron diffused. Graph (b) plots $J_{0 \mathrm{e}}$ as a function of time for samples exposed to dry-heat and room-ambient conditions. For comparison, the degradation data presented by Thomson and McIntosh ${ }^{15}$ are included. The specific storage conditions are listed in the respective legends.
In Figure 4, we replot the measured $J_{0 \mathrm{e}}$ as a function of time for the samples that were measured in this work for (i) samples stored in damp heat (Fig. 4(a)), (ii) samples stored in room ambient (Fig. 4(b)), and (iii) samples stored in dry heat (Fig. 4(c)). For comparison, we include lines representing the upper and lower calculated $\mathrm{H}_{2} \mathrm{O}_{\text {int }}$ plotted against a second vertical axis (the right y-axis). The upper and lower limits of $\mathrm{H}_{2} \mathrm{O}_{\text {int }}$ were calculated from the uncertainty in the moisture diffusion coefficient. The $\mathrm{H}_{2} \mathrm{O}_{\text {int }}$ $\mathrm{y}$-axes have been equivalently scaled across the three plots.

(a) $\diamond J_{0 e}\left(85^{\circ} \mathrm{C} 85 \% \mathrm{RH}\right)---\mathrm{H}_{2} \mathrm{O}_{\text {int }}\left(85^{\circ} \mathrm{C} 85 \% \mathrm{RH}\right)$

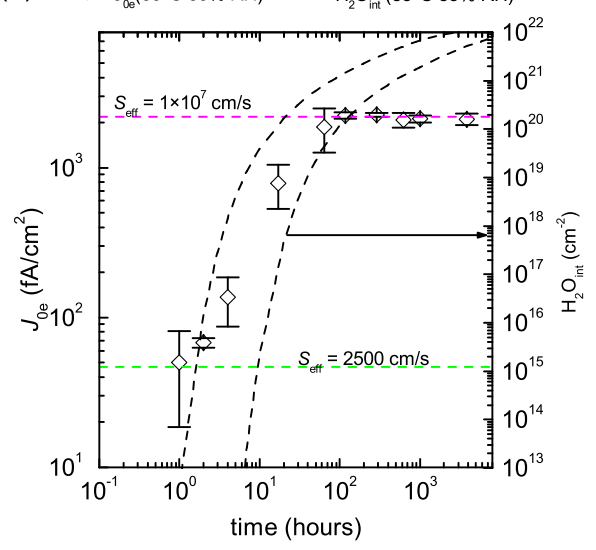

(b) $=J_{0 e}\left(25^{\circ} \mathrm{C} 15 \% \mathrm{RH}\right) \quad--\mathrm{H}_{2} \mathrm{O}_{\text {int }}\left(25^{\circ} \mathrm{C} 15 \% \mathrm{RH}\right)$
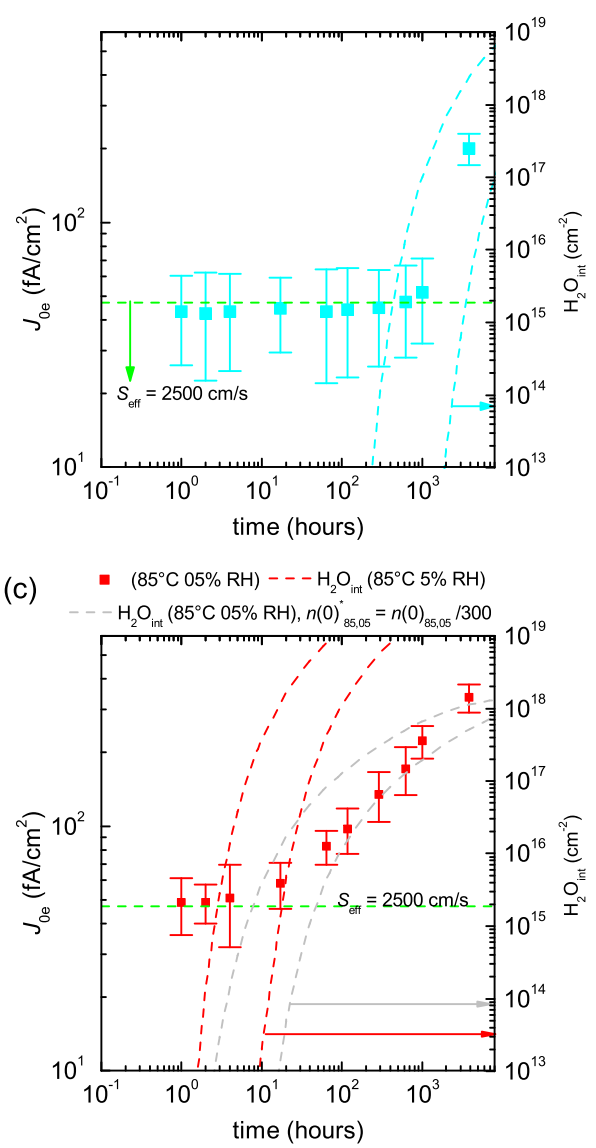

FIG. 4. Plots of $J_{0 \mathrm{e}}$ (left vertical axis) as a function of time for samples exposed to: damp heat (graph (a)), room-ambient (graph (b)) and dry-room ambient (graph (c)). Additionally, we have included lines representing the modelled $\mathrm{H}_{2} \mathrm{O}_{\text {int }}$ (right vertical axis) plotted as a function of time, equivalently scaled to the $J_{0 \mathrm{e}}$ axis throughout graphs (a), (b), and (c). 
We see a strong correlation with increasing $J_{0 \mathrm{e}}$ and $\mathrm{H}_{2} \mathrm{O}_{\text {int }}$ for samples stored at $85^{\circ} \mathrm{C}$ and $85 \%$ RH (Fig. 4(a)), as well as for $25^{\circ} \mathrm{C}$ and $15 \% \mathrm{RH}$ (Fig. 4(b). For samples stored in dry heat (Fig. 4(c)), there is not a good agreement when comparing $J_{0 \mathrm{e}}$ and $\mathrm{H}_{2} \mathrm{O}_{\mathrm{int}}$, using the method outlined in Sec. II C for ascertaining $n_{85,05}(0)$ (compare the dashed red lines to the closed red symbols). However as will be discussed, if $n_{85.05}(0)$ is arbitrarily scaled a good fit of $\mathrm{H}_{2} \mathrm{O}_{\text {int }}$ to measured $J_{0 \mathrm{e}}$ can be achieved (see grey dashed lines Fig. 4(c)).

For reference, we have used a $1 \mathrm{D}$ emitter model ${ }^{31}$ to calculate the $J_{0 \mathrm{e}}$ when the effective surface-recombination velocity $S_{\text {eff }}$ is set to its maximum level $\left(10^{7} \mathrm{~cm} / \mathrm{s}\right)$ as dictated by the thermal velocity of electrons in crystalline silicon. This simulation uses the ECV measured dopant profile (see Figure 1). The simulated maximum $J_{0 \mathrm{e}}$ is $2180 \mathrm{fA} / \mathrm{cm}^{2}$ and is plotted as the dashed horizontal line in Figure 4, and thus, the $J_{0 \mathrm{e}}$ cannot exceed this value irrespective of the number of interface defects. It agrees with the experimental saturated $J_{0 \mathrm{e}}$ attained by the samples exposed to damp heat (Fig. 4(a)). Conversely, the minimum $J_{0 \mathrm{e}}$, which is measured for samples in their pre-degraded state, is $47 \mathrm{fA} / \mathrm{cm}^{2}$. This initial $J_{0 \mathrm{e}}$ can be simulated with $S_{\text {eff }}$ of $2500 \pm 500 \mathrm{~cm} / \mathrm{s}$, which thereby provides an estimate of the surface-recombination velocity before moisture degradation. This value is shown as a green dashed line in each plot of Figure 4.

\section{DISCUSSION}

From this work it is clear that damp-heat exposure catastrophically degrades the thermal $\mathrm{SiO}_{2}$ passivation of $p^{+}$ surfaces. Degradation also occurs in samples stored under dry-heat and dry-room ambient conditions (see Table I for summary). Such degradation would in most cases lead to device failure. In particular, this effect is relevant to IBC and high-efficiency front-junction solar cell structures; ${ }^{3,4}$ indeed, $\mathrm{H}_{2} \mathrm{O}$ ingression and accumulation at the $\mathrm{SiO}_{2}-\mathrm{Si}$ interface are the likely cause of degraded open-circuit voltages observed in laboratory devices. ${ }^{19}$

We conclude that the $\mathrm{Si}-\mathrm{SiO}_{2}$ interface degradation can be explained by one physical driver: $\mathrm{H}_{2} \mathrm{O}$ ingression. Moisture causes depassivating reactions involving hydrogenous species at the $\mathrm{Si}-\mathrm{SiO}_{2}$ interface. Further, we find from the repairing of the interface when the samples were removed from damp heat to dry heat that the effect of the depassivation reactions are at least partially reversible and are likely explained by the removal of moisture from the $\mathrm{Si}-\mathrm{SiO}_{2}$ interface.

On a molecular level, the degradation process can be explained as proceeding in three stages. First is the diffusion of water vapor into the amorphous $\mathrm{SiO}_{2}$ film, as demonstrated by first-principle density-function simulations whereby $\mathrm{H}_{2} \mathrm{O}$ migrates through large voids and ring structures in the $\mathrm{SiO}_{2}$ layer. ${ }^{7}$ Second, the amorphous $\mathrm{SiO}_{2}$ film hosts a range of local environments providing low-energy reaction pathways for $\mathrm{H}_{2} \mathrm{O}$ dissociation. ${ }^{8,32}$ Third, dissociated $\mathrm{H}_{2} \mathrm{O}$ species react with the $\mathrm{Si}-\mathrm{SiO}_{2}$ interface ${ }^{33-35}$ creating and deactivating electronic defects.

When comparing the effect of damp heat on $p^{+}$surfaces to $n^{+}$surfaces (see Figure 3 top graph), we find that the degradation is more severe for $p^{+}$surface. One explanation for this observation is that the defect created by the reaction of moisture at the $\mathrm{Si}-\mathrm{SiO}_{2}$ interface has a significantly larger capture-cross section for electrons (the minority carrier in $p^{+}$ regions) than for holes. Such an explanation has previously been discussed in the context of room-ambient exposure. ${ }^{36}$ We note a considerable difference between recorded degradation of samples stored in dry-room ambient (this work) compared to previous measurements of room temperature degradation. ${ }^{15}$ These differences could be due to (1) the samples measured in the previous study were not stored in a container with drying chips but in room ambient (30\%-40\% $\mathrm{RH})$, and (2) the surface dopant profiles were not the same.

From Figure 4 where we have compared calculated $\mathrm{H}_{2} \mathrm{O}_{\text {int }}$ to $J_{0 \mathrm{e}}$, we find that there is a strong correlation with the increase in $J_{0 \mathrm{e}}$, for two of three storage conditions. Considering first the cases of damp-heat (Fig. 4(a)) and dry-ambient exposure (Fig. 4(b)), initially the $J_{0 \mathrm{e}}$ measured is not correlated to the changing $\mathrm{H}_{2} \mathrm{O}_{\text {int }}$; in this case there has not been enough moisture supplied to the interface to cause significant degradation. As $\mathrm{H}_{2} \mathrm{O}_{\text {int }}$ increases above $2 \times 10^{15} \mathrm{~cm}^{-2}$, there is a correlation between increasing $J_{0 \mathrm{e}}$ and $\mathrm{H}_{2} \mathrm{O}_{\text {int }}$. The correlation is maintained until, in the case of damp heat exposure, the $J_{0 \mathrm{e}}$ saturates $\left(\sim 2200 \mathrm{fA} / \mathrm{cm}^{2}\right)$. This divergence is related to the $\mathrm{Si}-\mathrm{SiO}_{2}$ interface having degraded to such an extent that the recombination in the diffused region is no longer limited by the defect at the interface but the diffusion of minority carriers to the surface. Hence, there is no longer any relationship between $J_{0 \mathrm{e}}$ and $\mathrm{H}_{2} \mathrm{O}_{\text {int }}$.

When comparing our calculated $\mathrm{H}_{2} \mathrm{O}_{\text {int }}$ with $J_{0 \mathrm{e}}$ for dry-heat exposure (Fig. 4(c)), we find poor correlation. Although the degradation commences when the calculated $\mathrm{H}_{2} \mathrm{O}_{\text {int }}$ exceeds $1 \times 10^{15} \mathrm{~cm}^{-2}$, the rate of degradation is slower than the rate of the $\mathrm{H}_{2} \mathrm{O}_{\text {int }}$ increases. We find that if the surface concentration $n_{85,05}(0)$ is reduced by a factor of 300 a good correlation between $J_{0 \mathrm{e}}$ and the calculated $\mathrm{H}_{2} \mathrm{O}_{\text {int }}$ is calculated (grey lines in Fig. 4(c)). This infers that either our method for determining $n_{85,05}(0)$ is invalid for the dry-heat storage, or that in the case of dry heat, the degradation is not caused solely by moisture ingression.

\section{CONCLUSIONS}

In this paper, we have experimentally compared the effect exposure to damp-heat, dry-heat, and dry-room ambient conditions on thermal $\mathrm{SiO}_{2}$ passivated $p^{+}$silicon surfaces. We find that although the degrading effect varies vastly in time scale and magnitude, the reactions can be explained by the ingression of moisture. We arrive at this conclusion by calculating $\mathrm{H}_{2} \mathrm{O}_{\text {int }}$ and comparing it to measurements of the $J_{0 \mathrm{e}}$. We note degradation is observed with dry-ambient storage but can take years to saturate. In this instance, damp-heat accelerated testing is an excellent test to determine the stability of the $\mathrm{Si}-\mathrm{SiO}_{2}$ interface. The magnitude of the degradation observed would easily cause catastrophic degradation in most devices. Hence, a capping layer that a capable of preventing moister ingression, such as silicon nitride, is essential when using thermal oxides on $p^{+}$ surfaces. 
${ }^{1}$ W. Füssel, M. Schmidt, H. Angermann, G. Mende, and H. Flietner, Nucl. Instrum. Methods Phys. Res., Sect. A 377(2-3), 177 (1996).

${ }^{2}$ J. Schmidt, A. Merkle, R. Bock, P. P. Altermatt, A. Cuevas, N. Harder, B. Hoex, R. van de Sanden, E. Kessels, and R. Brendel, in Proceedings of the 23rd European Photovoltaic and Solar Energy Conversion, Valencia, Spain, 2008.

${ }^{3}$ R. M. Swanson, S. K. Beckwith, R. A. Crane, W. D. Eades, K. Young Hoon, R. A. Sinton, and S. E. Swirhun, IEEE Trans. Electron Devices 31(5), 661 (1984).

${ }^{4}$ J. Zhao, A. Wang, P. Altermatt, and M. A. Green, Appl. Phys. Lett. 66(26), 3636 (1995).

${ }^{5}$ C. R. Osterwald and T. J. McMahon, Prog. Photovoltaics 17, 11 (2009).

${ }^{6}$ M. D. Kempe, Sol. Energy Mater. Sol. Cells 90(16), 2720 (2006).

${ }^{7}$ T. Bakos, S. N. Rashkeev, and S. T. Pantelides, Phys. Rev. Lett. 88(5), 055508 (2002)

${ }^{8}$ I. G. Batyrev, M. P. Rodgers, D. M. Fleetwood, R. D. Schrimpf, and S. T. Pantelides, IEEE Trans. Nucl. Sci. 53(6), 3629 (2006).

${ }^{9}$ A. Stesmans, Phys. Rev. Lett. 70(11), 1723 (1993).

${ }^{10}$ A. Stesmans and V. V. Afanas'ev, J. Vac. Sci. Technol., B: Microelectron. Nanometer Struct. 16(6), 3108 (1998).

${ }^{11}$ L. Tsetseris, X. J. Zhou, D. M. Fleetwood, R. D. Schrimpf, and S. T. Pantelides, Appl. Phys. Lett. 86(14), 142103 (2005).

${ }^{12}$ S. T. Pantelides, L. Tsetseris, S. N. Rashkeev, X. J. Zhou, D. M. Fleetwood, and R. D. Schrimpf, Microelectron. Reliab. 47, 903 (2007).

${ }^{13}$ L. P. Johnson, K. R. McIntosh, B. S. Richards, H. Jin, B. Paudyal, and E. Klampaftis, in Proceedings of the 44th ANZSES conference, 2006.

${ }^{14}$ E. Klampaftis, K. R. McIntosh, and B. S. Richards, in Proceedings of the 22nd European Photovoltaic Solar Energy Conference, Milan, Italy, 2007.

${ }^{15}$ A. F. Thomson and K. R. McIntosh, Appl. Phys. Lett. 95(5), 052101 (2009).

${ }^{16}$ J. C. Bellet and K. R. McIntosh, in Proceedings of the 22nd European Photovoltaic Solar Energy Conference, Milan, Italy, 2007.

${ }^{17}$ K. R. McIntosh and X. Dai, Phys. Status Solidi A 208(8), 1931 (2011).
${ }^{18}$ Y. Larionova, V. Mertens, N.-P. Harder, and R. Brendel, Appl. Phys. Lett. 96(3), 032105 (2010)

${ }^{19}$ J. Zhao, J. Schmidt, A. Wang, G. Zhang, B. Richards, and M. Green, in Proceedings of the 3rd World Conference on Photovoltaic Energy Conversion, 2003.

${ }^{20}$ R. Bock, P. P. Altermatt, and J. Schmidt, in Proceedings of the 23rd European Photovoltaic Solar Energy Conference, Valencia, Spain, 2008.

${ }^{21}$ W. R. Thurber, R. L. Mattis, Y. M. Liu, and J. J. Filliben, J. Electrochem. Soc. 127(10), 2291 (1980).

${ }^{22}$ D. E. Kane and R. M. Swanson, in Proceedings of the 18th IEEE Photovoltaic Specialists Conference, Las Vagas, USA, 1985.

${ }^{23}$ H. Nagel, C. Berge, and A. G. Aberle, J. Appl. Phys. 86(11), 6218 (1999).

${ }^{24}$ R. A. Sinton, in Proceedings of the 23rd European Photovoltaic and Solar Energy Conversion, Valencia, Spain, 2008.

${ }^{25}$ A. Cuevas, Sol. Energy Mater. Sol. Cells 57(3), 277 (1999).

${ }^{26}$ H. Mäckel and K. Varner, Prog. Photovoltaics 21, 850-866 (2012).

${ }^{27}$ A. F. Thomson, Z. Hameiri, N. E. Grant, C. J. Price, Y. Di, and J. Spurgin, IEEE J. Photovoltaics 3, 1200-1207 (2013).

${ }^{28}$ A. J. Moulson and J. P. Roberts, Trans. Faraday Soc. 57(0), 1208 (1961).

${ }^{29}$ W. A. Lanford, C. Burman, and R. H. Doremus, Advances in Materials Characterization II, edited by R. L. Snyder, R. A. Condrate, Sr., and P. F. Johnson (Springer, US, 1985), Vol. 19, p. 203.

${ }^{30}$ M. Nogami and M. Tomozawa, Phys. Chem. Glasses 25(3), 4 (1984).

${ }^{31} \mathrm{~K}$. R. McIntosh and P. P. Altermatt, in 35th IEEE Photovoltaic Specialists Conference (PVSC), 2010, p. 002188.

${ }^{32}$ I. G. Batyrev, B. Tuttle, D. M. Fleetwood, R. D. Schrimpf, L. Tsetseris, and S. T. Pantelides, Phys. Rev. Lett. 100(10), 105503 (2008).

${ }^{33}$ S. N. Rashkeev, D. M. Fleetwood, R. D. Schrimpf, and S. T. Pantelides, Phys. Rev. Lett. 87(16), 165506 (2001)

${ }^{34}$ J. M. M. de Nijs, K. G. Druijf, V. V. Afanas'ev, E. van der Drift, and P. Balk, Appl. Phys. Lett. 65(19), 2428 (1994)

${ }^{35}$ C. R. Helms and E. H. Poindexter, Rep. Prog. Phys. 57, 791 (1994).

${ }^{36}$ A. F. Thomson and K. R. McIntosh, in Proceedings of the 24th European Photovoltaic and Solar Energy Conversion, Hamburg, Germany, 2009. 